\title{
Activation of innate immunity by lysozyme fibrils is critically dependent on cross- $\beta$ sheet structure
}

\author{
Adelin Gustot • Vincent Raussens • Morgane Dehousse • \\ Mireille Dumoulin • Clare E. Bryant • \\ Jean-Marie Ruysschaert • Caroline Lonez
}

Received: 14 September 2012 / Revised: 25 November 2012 / Accepted: 12 December 2012 / Published online: 19 January 2013

(C) Springer Basel 2013

\begin{abstract}
Inflammation occurs in many amyloidoses, but its underlying mechanisms remain enigmatic. Here we show that amyloid fibrils of human lysozyme, which are associated with severe systemic amyloidoses, induce the secretion of pro-inflammatory cytokines through activation of the NLRP3 (NLR, pyrin domain containing 3) inflammasome and the Toll-like receptor 2 , two innate immune receptors that may be involved in immune responses associated to amyloidoses. More importantly, our data clearly suggest that the induction of inflammatory responses by amyloid fibrils is linked to their intrinsic structure, because the monomeric form and a non-fibrillar type of lysozyme aggregates are both unable to trigger cytokine secretion. These lysozyme species lack the so-called cross- $\beta$ structure, a characteristic structural motif common to all amyloid fibrils irrespective of their origin. Since fibrils of other bacterial and endogenous proteins have been shown to trigger immunological responses, our observations suggest that the cross- $\beta$ structural signature might be recognized as a generic danger signal by the immune system.
\end{abstract}

Keywords Amyloid-induced inflammation - Toll-like receptors $\cdot$ NLRP3 inflammasome $\cdot$ Cross- $\beta$ structure

\footnotetext{
A. Gustot $(\bowtie) \cdot$ V. Raussens $\cdot$ J.-M. Ruysschaert $\cdot$ C. Lonez Laboratory of Structure and Function of Biological Membranes, Université Libre de Bruxelles (ULB), 1050 Brussels, Belgium e-mail: adelingustot@hotmail.com; agustot@ulb.ac.be

M. Dehousse $\cdot$ M. Dumoulin

Laboratory of Enzymology and Protein Folding, Centre for Protein Engineering, University of Liège, 4000 Liege, Belgium

C. E. Bryant · C. Lonez

Department of Veterinary Medicine, University

of Cambridge, Cambridge CB3 OES, UK
}

\author{
Abbreviations \\ A $\beta \quad$ Amyloid $\beta$ \\ ASC Apoptosis speck-like protein containing a \\ caspase-recruitment domain \\ BMDM Bone marrow-derived macrophage \\ FTIR Fourier-transformed infrared spectroscopy \\ IL-1 $\beta \quad$ Interleukin-1 $\beta$ \\ LPS Lipopolysaccharide \\ NF-кB Nuclear factor-kappa B \\ NLR Nucleotide oligomerization domain-like receptor \\ NLRP3 NLR, pyrin domain containing 3 \\ PMA Phorbol 12-myristate 13-acetate \\ PRR Pattern-recognition receptor \\ TEM Transmission electron microscopy \\ ThT Thioflavin T \\ TLR Toll-like receptor \\ TNF- $\alpha$ Tumor necrosis factor- $\alpha$
}

\section{Introduction}

Amyloidoses are a set of human diseases characterized by the deposition of aggregated proteins in a variety of tissues and organs. To date, over 20 different proteins have been associated with human amyloidoses [1]. Strikingly, despite their different sequences, all these proteins form similar deposits sharing the same morphology, consisting of unbranched fibrils [2]. This typical fibrillar morphology arises from a common structural architecture known as cross- $\beta$ structure, which consists of ordered pileups of $\beta$-sheets, with $\beta$-strands perpendicular to the fibril axis [3]. In neurodegenerative amyloidoses such as Alzheimer's and Parkinson's diseases [4, 5], the presence of amyloid deposits in the brain triggers uncontrolled neuroinflammation via activation of the brain resident immune cells (microglia) [6], a process 
which actively contributes to disease progression. The presence of inflammatory markers such as activated microglia or elevated levels of proinflammatory cytokines around the amyloid aggregates is a known feature of many amyloidoses. In a growing number of cases, such as Alzheimer's disease [7], Parkinson's disease [8], or type II diabetes [9], it has been shown that the aggregated protein itself triggers an inflammatory response, demonstrating that the inflammation associated with these diseases arises, at least in part, from the presence of the amyloid aggregates themselves. Understanding the molecular mechanisms by which amyloid deposits trigger inflammation might therefore provide new clues to develop therapeutic strategies to combat these important diseases.

Many cytokines are expressed by immune cells in the brain of patients suffering from neurodegenerative diseases.

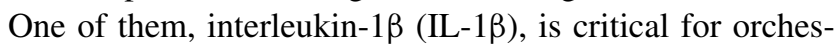
trating the inflammatory response [10], by inducing fever, recruiting immune cells, and regulating cell death. IL-1 $\beta$ production involves a two-step mechanism [10]. The first step consists in the induction of the IL- $1 \beta$ inactive precursor (pro-IL-1 $\beta$ ) expression through activation of the transcription factor NF- $\kappa B$. Generally, this step is reached by activating a Toll-like receptor (TLR), a subgroup of the pattern recognition receptors (PRRs) used by the innate immune system to detect pathogens and endogenous danger signals [11]. The second step requires a second signal, independent from the first one, which induces the assembly of large multiprotein complexes called inflammasomes, which finally process pro-IL- $1 \beta$ into mature IL- $1 \beta$. Inflammasomes are generally composed of three elements: (1) a nucleotide oligomerization domain-like receptor (NLR), which senses the activating signal, (2) pro-caspase-1, which cleaves pro-IL-1 $\beta$, and (3) in most cases, the protein ASC (apoptosis speck-like protein containing a caspaserecruitment domain), which bridges pro-caspase-1 and the NLR [12]. Upon activation of the NLR, inflammasome elements oligomerize to form large complexes mediating cleavage of pro-IL-1 $\beta$.

To date, three amyloid aggregates have been shown to induce the secretion of IL- $1 \beta$ through inflammasome activation: the amyloid- $\beta$ peptide (A $\beta$ ) [7], superoxide dismutase 1 (SOD1) [13], and the islet amyloid polypeptide (IAPP) [9, 14]. However, the exact nature of the aggregates that actually activate the inflammasome is confusing, as the structure of the incriminated species has not been investigated.

Lysozyme systemic amyloidosis is a non-neuropathic hereditary disorder caused by the deposition of amyloid fibrils made of mutational variants of lysozyme [15]. Accumulation of these insoluble aggregates in kidney, liver, or spleen is usually slow, but ultimately leads to organ failure and is always fatal. The mechanism of amyloid fibril formation by lysozyme has been extensively studied, and is increasingly well understood at the molecular level [16]. However, the effects generated by these aggregates at the cellular level are poorly understood.

Here, we analyze the cellular responses induced by lysozyme amyloid fibril administration to immune cells, and focus mainly on pro-inflammatory cytokine secretion. We show that lysozyme fibrils activate TLR2 and NLRP3 (NLR, pyrin domain containing 3), identifying two innate immune receptors that may be involved in the pathology of systemic non-neuropathic amyloidoses. Monomers and non-fibrillar aggregates of lysozyme, however, fail to stimulate TLR2 and NLRP3. In these species, lysozyme adopts different conformations than in fibrils, lacking the characteristic cross- $\beta$ structural motif, suggesting that lysozyme fibril-induced inflammation is based around their intrinsic structure. Since fibrils of other bacterial and endogenous proteins trigger immunological responses, our observations suggest that the cross- $\beta$ sheet structure found in all amyloid fibrils may constitute a generic pattern sensed by innate receptors.

\section{Materials and methods}

Reagents and cell strains

Human embryogenic kidney cells (HEK 293) were obtained from ATCC (Manassas, VA, USA). THP1 cells (human acute monocytic leukemia cell line) were obtained from HPA Cultures (Salisbury, United Kingdom). THP1-XBlue cells, ASC-deficient and NLRP3-deficient THP1 cells, Normocin, Zeocin, HygroGold, Ultrapure flagellin from S. typhimurium, FSL-1, Ultrapure standard lipopolysaccharide (LPS) from E. coli 0111:B4, Pam3CysSerLys4 (Pam3CSK4), poly(dA:dT) (provided complexed with the cationic lipid Lyovec to facilitate its uptake) and anti-TLR antibodies were from InvivoGen (San Diego, CA, USA). RPMI (Roswell Park Memorial Institute) and DMEM (Dulbecco's modified Eagle's medium) media, heat-inactivated fetal bovine serum (FBS), L-glutamine, sodium pyruvate, penicillin, streptomycin, and $\beta$-mercaptoethanol were from Lonza (Basel, Switzerland). Bay 11-8072, Phorbol 12-myristate 13-acetate (PMA) and thioflavin $\mathrm{T}$ were purchased from Sigma-Aldrich (St. Louis, MO, USA), and z-VAD-fmk was from Biovision (Mountain View, CA, USA). The horseradish peroxidase-conjugated secondary polyclonal antibody to rabbit was from Cell Signaling Technology (Danvers, MA, USA). The human IL- $1 \beta$ polyclonal antibody and ELISA kits were from R\&D Systems (Minneapolis, MN, USA). The human caspase- 1 polyclonal antibody and the horseradish peroxidase-conjugated secondary polyclonal antibody to sheep were from Abcam (Cambridge, United Kingdom). 
Preparation of lysozyme samples

Human lysozyme was expressed in Pichia pastoris, purified and stored lyophilized as described previously [17].

\section{Monomer preparation}

The lyophilized protein was just resuspended in water at the desired concentration (usually around $\mu \mathrm{M}$ ).

\section{Formation of fibrils}

Stock solutions of lysozyme were prepared in $0.1 \mathrm{M}$ tri-sodium citrate buffer $(\mathrm{pH} 5.5)$, filtered $(0.22-\mu \mathrm{m}$ pore size) and diluted to a final concentration of $0.1 \mathrm{mg} / \mathrm{ml}$ in $0.1 \mathrm{M}$ tri-sodium citrate buffer (pH 5.5) containing $8 \mathrm{M}$ urea. Samples $(24 \times 1.5 \mathrm{ml})$ were incubated at $60^{\circ} \mathrm{C}$, with stirring, in a Cary100 spectrophotometer equipped with a Peltier-controlled holder (Varian). Protein aggregation was monitored through changes in turbidity at $600 \mathrm{~nm}$. Under these conditions, the aggregation was completed within $\sim 1 \mathrm{~h}$. Fibril suspensions were centrifuged $(17,100 \times g$ for $30 \mathrm{~min}$ ) and the pellets subjected to three washing cycles in $1.5 \mathrm{ml}$ milliQ water. Between each cycle, the suspensions were centrifuged and the supernatants discarded to remove soluble protein, buffer, and urea. The pellet obtained after the last cycle was resuspended in milliQ water at a concentration of $\sim 2 \mathrm{mg} / \mathrm{ml}$ and kept at $4{ }^{\circ} \mathrm{C}$ until further analysis.

\section{Formation of amorphous aggregates}

Amorphous aggregates were formed as previously described [18] by incubating lysozyme $(0.3 \mathrm{mg} / \mathrm{ml})$ overnight at $42{ }^{\circ} \mathrm{C}$ in phosphate buffered saline (PBS, $\mathrm{pH}$ 7.5) containing $20 \mathrm{mM}$ DTT. The aggregate suspension was centrifuged $(17,100 \times g$ for $30 \mathrm{~min})$ and the pellet subjected to three washing cycles in milliQ water. Between each cycle, the suspension was centrifuged and the supernatant discarded to remove soluble protein and buffer. The pellet obtained after the last cycle was resuspended in milliQ water at $\sim 2 \mathrm{mg} / \mathrm{ml}$ and kept at $4{ }^{\circ} \mathrm{C}$ until analyzed.

To determine the amount of fibrillar and amorphous aggregates, the amount of lysozyme present in the supernatant of each washing step was subtracted from the total amount of protein engaged in the aggregation process. Protein concentration in each supernatant was determined by measuring the absorbance at $280 \mathrm{~nm}$ using a molar extinction coefficient of $37,689 \mathrm{M}^{-1} \mathrm{~cm}^{-1}$.

\section{Cell culture}

THP1 cells were cultured in RPMI 1640 supplemented with $10 \%$ heat-inactivated FBS, 2 mM L-glutamine, $1 \mathrm{mM}$ sodium pyruvate, $50 \mathrm{U} / \mathrm{ml}$ penicillin, $50 \mu \mathrm{g} / \mathrm{ml}$ streptomycin, and $50 \mu \mathrm{M} \beta$-mercaptoethanol. ASC-deficient and NLRP3-deficient THP1 cells were cultured in the same medium, but supplemented with Normocin and HygroGold. After stimulation, cell culture supernatants were collected and assayed for human IL- $1 \beta$ or human TNF- $\alpha$ (tumor necrosis factor- $\alpha$ ) by ELISA (enzyme-linked immunosorbent assay) according to the manufacturer's instructions. THP1-XBlue cells, which express a secreted embryonic alkaline phosphatase (SEAP) when NF- $\kappa \mathrm{B}$ is activated, were cultured in the same medium as THP1 cells, complemented with $100 \mu \mathrm{g} / \mathrm{ml}$ Normocin and $200 \mu \mathrm{g} / \mathrm{ml}$ Zeocin. The phosphatase produced by THP1-XBlue cells upon incubation with NF- $\mathrm{KB}$ activators was detected using the Quanti Blue medium (InvivoGen, San Diego, CA, USA), according to the manufacturer's instructions. For experiments with priming, THP1 cells were first resuspended in fresh medium $\left(5 \times 10^{5}\right.$ cells $\left./ \mathrm{ml}\right)$ containing $0.5 \mu \mathrm{M}$ PMA the day prior to stimulation, seeded in 24 -well plates $\left(5 \times 10^{5}\right.$ cells/well), and incubated for $3 \mathrm{~h}$ at $37{ }^{\circ} \mathrm{C}$. The medium was then exchanged for PMA-free medium and the cells were further incubated overnight. The next day, cells were washed with serum-free medium and incubated for $6 \mathrm{~h}$ with lysozyme samples $(10 \mu \mathrm{M}$ unless stated otherwise) in serum-free medium. When specified, the stimulation was done in the presence of $130 \mathrm{~nm} \mathrm{KCl}, 20 \mu \mathrm{M} \mathrm{z}$-VAD-fmk or $20 \mu \mathrm{M}$ Bay 11-7082. For experiments without priming, THP1 cells were resuspended in fresh medium (final concentration $6 \times 10^{5}$ cells $\left./ \mathrm{ml}\right)$, plated in $96-$ well plates $\left(10^{5}\right.$ cells $/$ well $)$ or 24 -well plates $\left(5 \times 10^{5}\right.$ cells/well $)$ and directly incubated for $6 \mathrm{~h}$ with either lysozyme monomers, fibrils, or amorphous aggregates ( $5 \mu \mathrm{M}$ unless stated otherwise), ultrapure LPS (5 ng/ml), Pam3CSK4 (1 ng/ml), FSL-1 (100 ng/ml), or ultrapure flagellin $(100 \mathrm{ng} / \mathrm{ml})$ in fresh medium. When anti-TLR antibodies and Bay 11-7082 were used, THP1 cells were incubated for $1 \mathrm{~h}$ with the antibodies $(20 \mu \mathrm{g} / \mathrm{ml})$ or Bay 11-7082 $(20 \mu \mathrm{M})$ prior to the addition of activators.

Primary bone marrow-derived macrophages (BMDMs) were isolated from femurs and tibiae of $\mathrm{NLRP}^{-/}$C57BL/6 mice or their WT littermates and cultured in BMDM medium in Petri dishes. BMDMs were cultured in DMEM supplemented with $10 \%(\mathrm{v} / \mathrm{v})$ FBS, $8 \mathrm{mM}$ L-glutamine, $10 \mu \mathrm{g} / \mathrm{ml}$ gentamicin, and $20 \%(\mathrm{v} / \mathrm{v})$ of L929-conditioned medium (supernatant taken from L929 cells, a murine M-CSF-producing cell line). Once cells had become confluent after approximately $8-10$ days, they were harvested by scraping and seeded in 96-well $\left(5 \times 10^{5}\right.$ cells $/ \mathrm{ml}-200 \mu \mathrm{l} /$ well $)$ plates with fresh medium. They were then incubated at $37{ }^{\circ} \mathrm{C}-5 \% \mathrm{CO}_{2}$ overnight to allow the cells to adhere to the plate. Cells were then primed for $3 \mathrm{~h}$ with $100 \mathrm{ng} / \mathrm{ml}$ LPS or medium (unprimed cells), and stimulated for $21 \mathrm{~h}$ with the ligands. After stimulation, cell culture supernatants were collected and assayed for mouse IL- $1 \beta$ or mouse TNF- $\alpha$ by 
ELISA using the BD OptEIA sets from BD Biosciences (San Diego, CA, USA) or DuoSet ELISA kits from R\&D Systems, respectively, according to the manufacturer's instructions.

HEK 293 cells were maintained in DMEM supplemented with $10 \%$ FBS, 2 mM L-glutamine, $100 \mathrm{U} / \mathrm{ml}$ penicillin, and $100 \mu \mathrm{g} / \mathrm{ml}$ streptomycin. After $48 \mathrm{~h}$, cells were stimulated for $6 \mathrm{~h}$ with the different lysozyme species, UltraPure LPS (100 ng/ml) or Pam3CSK4 (200 ng/ml) diluted in serum-free DMEM. Cells were then washed with PBS and then lysed with passive lysis buffer (Promega, Madison, WI, USA). Luciferase and Renilla activity were then quantified on a FLUOStar Omega plate reader (BMG Labtech, Ortenberg, Germany) using luciferase reagent $\left(20 \mathrm{mM}\right.$ Tricine, $2.67 \mathrm{mM} \mathrm{MgSO}_{4} .7 \mathrm{H}_{2} \mathrm{O}$, $0.265 \mathrm{mM}\left(\mathrm{MgCO}_{3}\right)_{4} \mathrm{Mg}(\mathrm{OH})_{2} .5 \mathrm{H}_{2} \mathrm{O}, 0.1 \mathrm{mM}$ EDTA (ethylenediaminetetraacetic acid), $33.3 \mathrm{mM}$ DTT (dithiothreitol), $530 \mu \mathrm{M}$ ATP (adenosine-5'-triphosphate), $270 \mu \mathrm{M}$ acetyl CoEnzyme A (lithium salt), $470 \mu \mathrm{M}$ Luciferin (Biosynth, Staad, Switzerland), $\mathrm{pH} 7.8$, dissolved two times in water before use) or coelenterazine reagent (coelenterazine (Biosynth, Staad, Switzerland) dissolved in ethanol at $1 \mathrm{mg} / \mathrm{ml}$ diluted 500 times in PBS before use). Luciferase luminescence intensity was normalized to Renilla luminescence intensity and data were expressed as fold induction as compared to non-induced control.

\section{Cell transfection}

Cells were transfected as previously described [19]. Cells were seeded at $4 \times 10^{4}$ cells $/ \mathrm{ml}$ in 96-well plates and transiently transfected 3 days later. For TLR 4 activation, expression vectors containing cDNA encoding TLR4, MD2, and CD14 (1 ng/well of each), a NF-кB transcription reporter vector encoding firefly luciferase (5 ng/well pNF-кB-luc from Clontech, Saint-Germain-en-Laye, France), and a constitutively active reporter vector encoding Renilla luciferase (5 ng/well phRG-TK; Promega, Madison, WI, USA), together with empty vector to ensure that an optimal amount of DNA was mixed with jetPEI (Polyplus transfection, New York, NY, USA) according to the manufacturer's instructions. For TLR2 activation, expression vectors coding for TLR2 with and without CD14 were transfected with reporter plasmids and empty plasmids.

\section{Western blots}

Cell supernatants were concentrated using 10-kDa cut-off Amicon filter devices (Microcon from Millipore, Billerica, MA, USA), resuspended in Laemmli buffer, and heated at $95{ }^{\circ} \mathrm{C}$ for $5 \mathrm{~min}$. Samples were separated by sodium dodecyl sulfate polyacrylamide gel electrophoresis (SDS/PAGE) (14\% acrylamide) and subsequently transferred onto nitrocellulose membranes, which were then blocked for $1 \mathrm{~h}$ in $5 \%$ non-fat dry milk in Tris buffered saline (TBS)/Tween 20 buffer ( $10 \mathrm{mM}$ Tris/HCl, pH 8, $150 \mathrm{mM} \mathrm{NaCl}, 0.0625 \%$ Tween 20). Membranes were then incubated with either the goat polyclonal anti-human IL- $1 \beta$ antibody $(0.2 \mu \mathrm{g} / \mathrm{ml})$ or the rabbit polyclonal anti-human caspase-1 antibody $(2 \mu \mathrm{g} / \mathrm{ml})$. Detection was carried out using either horseradish peroxidase-conjugated anti-goat antibody $(1: 2,000)$ or horseradish peroxidase-conjugated anti-rabbit antibody $(1: 1,000)$ and the Supersignal West Pico Chemiluminescent Substrate (Pierce Biotechnology, Rockford, IL, USA). Pictures were recorded and analyzed using the ImageQuant 400 gel imager and ImageQuant TL software (GE Healthcare, Little Chalfont, United Kingdom).

\section{Dot blots}

Amounts of $5 \mu 1$ and $10 \mu l$ of lysozyme monomers, fibrils, and amorphous aggregates $(1 \mathrm{mg} / \mathrm{ml})$ were spotted on three nitrocellulose membranes (Millipore, Billerica, MA, USA). These membranes were incubated overnight at $4{ }^{\circ} \mathrm{C}$ in TBS buffer ( $\mathrm{pH} 7.5$ ) supplemented with $3 \%$ ovalbumin (Sigma-Aldrich (St. Louis, MO, USA)). After three washing steps in TBS with $0.001 \%$ Tween 20 (TBST), the membranes were then respectively incubated for $1 \mathrm{~h}$ at room temperature with either (1) a 1:1,000 dilution of polyclonal rabbit anti-lysozyme antiserum (Washington Biotechnology Inc., Columbia, MD, USA), (2) a 1:5,000 dilution of the rabbit anti-oligomers A11 antibody (gift from Dr. C. Glabe, UC Irvine, CA, USA) and (3) a 1:5,000 dilution of the antifibrils OC antibody (gift from Dr. C. Glabe). After three washing steps in TBST, membranes were incubated with an alkaline phosphatase-conjugated goat anti-rabbit IgG (BioRad, Hercules, CA, USA) (dilution 1:3,000 $1 \%$ bovine serum albumin in TBST) for $1 \mathrm{~h}$ at room temperature. Colorimetric detection of alkaline phosphatase activity was performed using 5-bromo-4-chloro-3-indonyl-phosphatase in conjugation with nitro blue tetrazolium.

Fourier-transformed infrared spectroscopy (FTIR)

Infrared spectra were recorded on an Equinox 55 infrared spectrophotometer (Bruker Optics) equipped with a Golden Gate reflectance accessory (Specac). The internal reflection element was a diamond crystal $(2 \times 2 \mathrm{~mm})$ with an aperture angle of $45^{\circ}$ that yielded a single internal reflection. A total of 128 accumulations were performed to improve the signal-to-noise ratio. The spectrometer was continuously purged with dried air. Spectra were recorded at a resolution of $2 \mathrm{~cm}^{-1}$. Then $2 \mu \mathrm{l}(\sim 10 \mathrm{ng})$ of lysozyme samples were spread on the diamond surface and excess water was removed under $\mathrm{N}_{2}$ flow. The self-deconvolution was carried out using a Lorentzian line shape for the deconvolution and 
a Gaussian line shape for the apodization. To quantify the area of the different components of amide I revealed by the self-deconvolution, a least-squares iterative curve fitting was performed to fit a mixture of Gaussian and Lorentzian line shapes to the spectrum between 1,700 and $1,600 \mathrm{~cm}^{-1}$. Prior to curve fitting, a straight baseline passing through the ordinates at 1,700 and $1,600 \mathrm{~cm}^{-1}$ was subtracted. To avoid introducing artifacts due to the self-deconvolution procedure, the fitting was performed on the non-deconvoluted spectrum. The proportion of a particular structure was computed to be the sum of the area of all fitted bands having their maximum in the frequency region where that structure occurs divided by the area of all Gaussian/Lorentzian bands having their maximum between 1,700 and $1,600 \mathrm{~cm}^{-1}$ $[20,21]$.

\section{Thioflavin $\mathrm{T}$ binding}

A protein sample of $5 \mu \mathrm{l}$ (appropriately diluted to reach a final protein concentration of $0.8 \mu \mathrm{M}$ ) was added to $1.5 \mathrm{ml}$ of a $50 \mu \mathrm{M}$ thioflavin $\mathrm{T}$ (ThT) solution (prepared in $10 \mathrm{mM}$ sodium phosphate buffer, $150 \mathrm{mM} \mathrm{NaCl}, \mathrm{pH}$ 7). ThT binding was then monitored by exciting the sample at $440 \mathrm{~nm}$ (slit width $5 \mathrm{~nm}$ ) and recording the emission fluorescence spectrum from 450 to $600 \mathrm{~nm}$ (at a rate of $1,200 \mathrm{~nm} / \mathrm{min}$, slit width $5 \mathrm{~nm}$ ). Measurements were carried out at $25^{\circ} \mathrm{C}$ with stirring, on a Cary Eclipse spectrofluorometer equipped with a Peltier-controlled holder (Varian, Mulgrave, Australia). For each sample, 20 fluorescence emission spectra were recorded, averaged, and corrected for background fluorescence of the ThT solution alone. The measurements were carried out at least in triplicate, and the averages were represented.

\section{Transmission electron microscopy (TEM)}

Samples $(10 \mu \mathrm{l})$ at a concentration of $0.2 \mathrm{mg} / \mathrm{ml}$ were left for 2 min on carbon-coated 400-mesh copper grids before being stained for 1 min with $2 \%$ uranyl acetate. The grids were then washed once with $2 \%$ uranyl acetate $(w / v)$ and finally, three times with milliQ water. Images were recorded on a Philips CEM100 transmission electron microscope operating at $100 \mathrm{kV}$.

\section{Results}

Characterization of two morphologically different lysozyme aggregates

Fibrils were prepared by incubating wild-type (WT) human lysozyme in acidic conditions (Materials and methods). The fibrillar nature of the aggregated species formed under these conditions was confirmed by negative stained transmission electron microscopy (TEM) (Fig. 1a, left). The structures observed include some well-resolved isolated fibrils (diameter of $\sim 13.5 \mathrm{~nm}$ ) although most fibrils appear to be incorporated into large bundles (diameter of $\sim 150 \mathrm{~nm}$ ). Such fibrils and ribbon structures have previously been observed with several amyloidogenic variants of lysozyme [22] and the wild-type protein [23].

In order to investigate the role of fibril structure in their inflammatory properties, we also prepared non-fibrillar lysozyme aggregates using reducing conditions [18]. TEM images of these aggregates (Fig. 1a, right) displayed a clearly different morphology to our standard fibrillar preparation. While lysozyme fibrils formed typical unbranched fibrils, aggregates prepared under reducing conditions assembled into larger amorphous aggregates of irregular shape, referred to as "amorphous aggregates" from now on in this paper.

The different morphologies of amorphous and fibrillar aggregates reflect distinct conformations of the polypeptide chain

The structure of our aggregates was examined by Fouriertransformed infrared spectroscopy (FTIR), a method particularly well suited to the study of proteins and protein aggregates [20,24]. Amide I, a specific region of the infrared spectrum of proteins located between 1,600 and $1,700 \mathrm{~cm}^{-1}$, is very sensitive to the secondary structure of proteins [20]. Deconvolution and curve-fitting of this region gives the percentage of content in each secondary structure type, as listed in Table 1. For fibrils and monomers, these percentages are in good agreement with those obtained in a previous work [23].

The monomeric sample (Fig. 1b, pink) exhibits a mixture of different structures, but mainly contains $\alpha$-helical and random structures (58\%), as shown by the single maximum around $1,650 \mathrm{~cm}^{-1}$. Lysozyme fibrils have the typical spectrum of amyloid fibrils: the major peak located at $1,625 \mathrm{~cm}^{-1}$ (Fig. 1b, cyan) is the signature of $\beta$-sheets, and the absence of a concomitant absorption peak at $1,695 \mathrm{~cm}^{-1}$ demonstrates that these $\beta$-sheets are parallel $[25,26]$, the relative orientation usually adopted by $\beta$-strands in the generic cross- $\beta$ architecture of amyloid fibrils [27, 28]. Random and helical structures $\left(1,650 \mathrm{~cm}^{-1}\right)$ are detected, as well as loops and turns $\left(1,670 \mathrm{~cm}^{-1}\right)$, but to a lesser extent than in the two other conformations. The spectrum of amorphous aggregates (Fig. 1b, blue) does not show the features present in the fibril spectrum. First, their $\beta$-sheet content is considerably reduced as compared with fibrils, dropping from 79 to $44 \%$ with a concomitant substantial enrichment in the other structures (Table 1). Secondly, the $\beta$-sheets found in amorphous aggregates are different from those of fibrils: the spectrum shows, in addition to the $1,625 \mathrm{~cm}^{-1}$ band, a peak at $1,695 \mathrm{~cm}^{-1}$ 

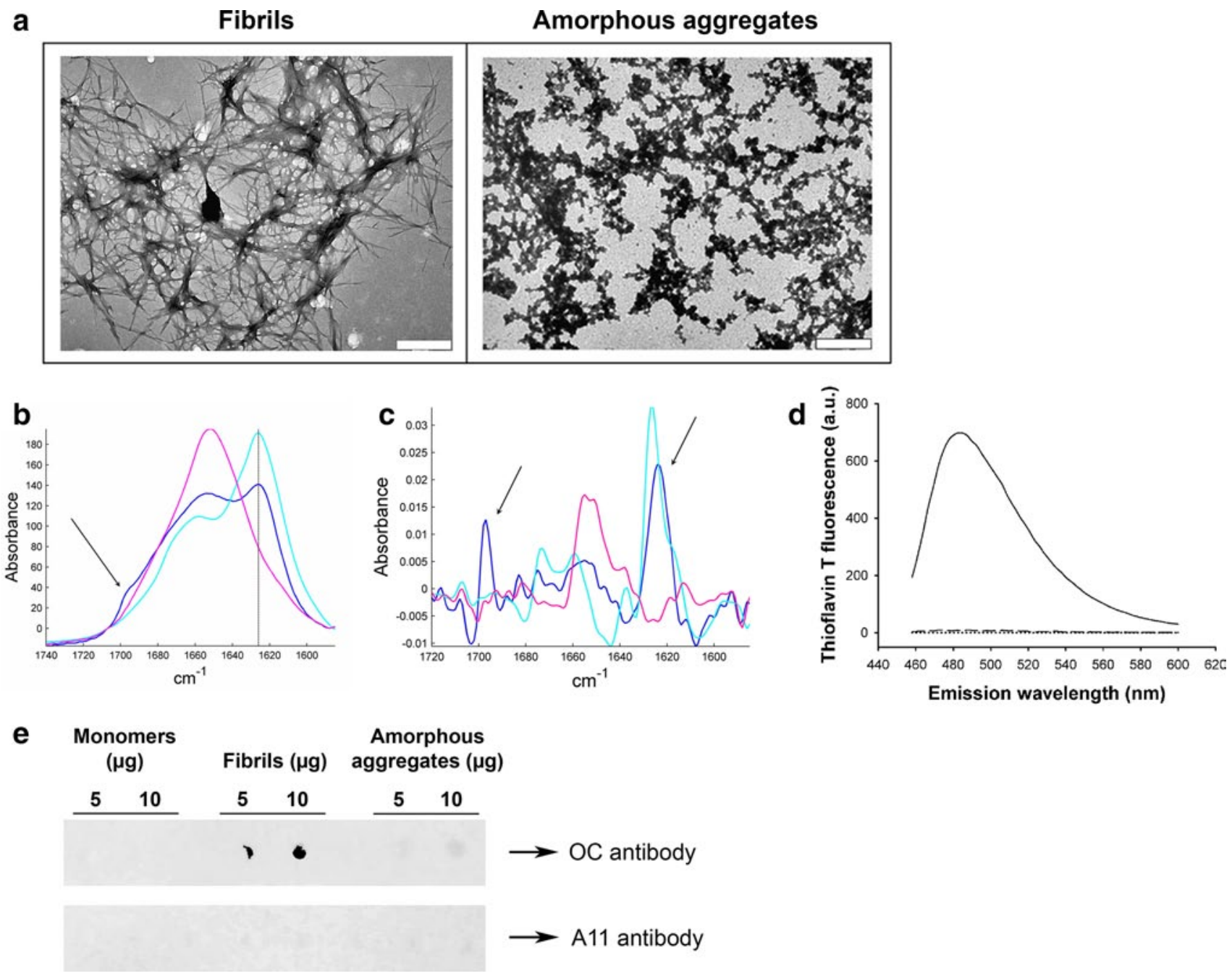

Fig. 1 Characterization of lysozyme species. a Negative stained TEM images of lysozyme fibrils (left) and amorphous aggregates (right). The scale bar represents $500 \mathrm{~nm}$. b Infrared spectrum of lysozyme monomers (pink), amorphous aggregates (blue), and fibrils (cyan). Spectra were scaled for identical Amide I area $\left(1,711-1,590 \mathrm{~cm}^{-1}\right)$. The $1,625 \mathrm{~cm}^{-1}$ peak (solid line) is characteristic of $\beta$-sheets, and the presence of an additional peak at $1,695 \mathrm{~cm}^{-1}$ (arrow) is the spectral signature of antiparallel $\beta$-sheets. $\mathbf{c} 2$ nd deriva-

(Fig. 1b, blue, arrow). The simultaneous presence of these two bands is the spectral signature of antiparallel $\beta$-sheets [29-31]. For further visualization of this antiparallel spectral signature, we examined the second derivative of the spectra (Fig. 1c). The concomitant presence of the 1,625 and $1,695 \mathrm{~cm}^{-1}$ peaks (arrows) appears very clearly with amorphous aggregates (Fig. 1c, blue), while the lysozyme fibril spectrum only have the $1,625 \mathrm{~cm}^{-1}$ peak (Fig. 1c, cyan).

These structural differences between fibrillar and amorphous aggregates were further supported by measuring the fluorescence of ThT, a dye which specifically fluoresces in the presence of the $\beta$-pleated sheet conformation of amyloid fibrils [32]. ThT fluorescence was not amplified in tive of the infrared spectra shown in $\mathbf{b}$ (same color code). For better visualization, those derivatives have been reversed. The arrows point to the 1,625 and $1,695 \mathrm{~cm}^{-1}$ peaks. $\mathbf{d}$ ThT fluorescence assay in the presence of $0.8 \mu \mathrm{M}$ of either lysozyme fibrils (solid line), monomers (dotted line), or amorphous aggregates (dashed line) $\left(\lambda_{\mathrm{ex}}: 440 \mathrm{~nm}\right)$. e Dot blot of lysozyme monomers (left), fibrils (middle), and amorphous aggregates (right) using the fibril-specific OC antibody (upper panel) or the oligomer-specific A11 antibody (lower panel)

the presence of amorphous aggregates (Fig. 1d, dashed), nor in the presence of monomers (Fig. 1d, dotted), whereas a strong fluorescence increase was detected in the presence of lysozyme fibrils (Fig. 1d, solid), confirming the fibrillar nature of these aggregates.

In addition, the conformation-dependent fibril-specific OC [33] antibody did not recognize amorphous aggregates, although it clearly detected lysozyme fibrils (Fig. 1e). Finally, the conformational A11 antibody raised against oligomers [34] did not recognize any lysozyme aggregates (Fig. 1e), ruling out any oligomeric contamination.

Taken together, these results provide strong evidence that while lysozyme fibrillar aggregates harboring high $\beta$-sheet 
Table 1 Secondary structure content of lysozyme in the three different states

\begin{tabular}{llll}
\hline $\begin{array}{l}\text { Secondary } \\
\text { structure }\end{array}$ & $\begin{array}{l}\text { Monomers } \\
(\%)\end{array}$ & $\begin{array}{l}\text { Fibrils } \\
(\%)\end{array}$ & $\begin{array}{l}\text { Amorphous } \\
\text { aggregates }(\%)\end{array}$ \\
\hline$\beta$-sheets & 15 & 79 & 44 \\
$\alpha$-helix/random & 58 & 14 & 29 \\
Loops/turns & 28 & 7 & 28 \\
\hline
\end{tabular}

The proportions of each secondary structure have been calculated from spectra shown in Fig. 1b, by deconvolution and curve fitting of the Amide I band, according to [20]

content with a parallel relative orientation of the $\beta$-strands adopt the typical cross- $\beta$ architecture found in all amyloid fibrils, amorphous aggregates do not present this characteristic architecture. Moreover, they highlight that the different morphologies adopted by these two types of lysozyme aggregates are associated with fundamentally different molecular conformations of the protein.

Fibrillar aggregates of lysozyme, but not amorphous aggregates, trigger IL- $1 \beta$ secretion

To investigate whether lysozyme aggregates were able to induce inflammatory responses, we incubated the human monocytic THP1 cell line with our lysozyme samples and tested their ability to induce the release of mature IL-1 $\beta$. To differentiate cells into macrophages and ensure strong expression of pro-IL-1 $\beta$, THP1 cells were first primed with PMA [12, 35]. Incubation with lysozyme fibrils then resulted in the secretion of high levels of IL-1 $\beta$ in a concentration-dependent manner (Fig. 2a), similarly to ATP or nigericin (Fig. 2a), two compounds that trigger proIL-1 $\beta$ processing through the NLRP3 inflammasome [36]. Non-aggregated lysozyme and amorphous aggregates, in contrast, did not induce any IL- $1 \beta$ secretion, even at the highest concentration (Fig. 2a). Immunoblot analysis confirmed the presence of cleaved IL- $1 \beta$ in cell supernatants when incubated with lysozyme fibrils but not with monomers or amorphous aggregates (Fig. 2b).

IL-1 $\beta$ production occurs through activation of caspase-1, the effector component of inflammasomes [12, 37]. Procaspase-1 cleavage was indeed induced by lysozyme fibrils in a concentration-dependent manner, while no cleaved caspase-1 was detected following incubation with the unaggregated protein or with amorphous aggregates (Fig. 2b). Finally, incubation of LPS-primed mouse primary bone marrow-derived macrophages (BMDMs) with fibrillar lysozyme also led to a concentration-dependent production of IL-1 $\beta$. Like in THP1 cells, lysozyme monomers and amorphous aggregates did not induce any cytokine secretion (Fig. 2c).
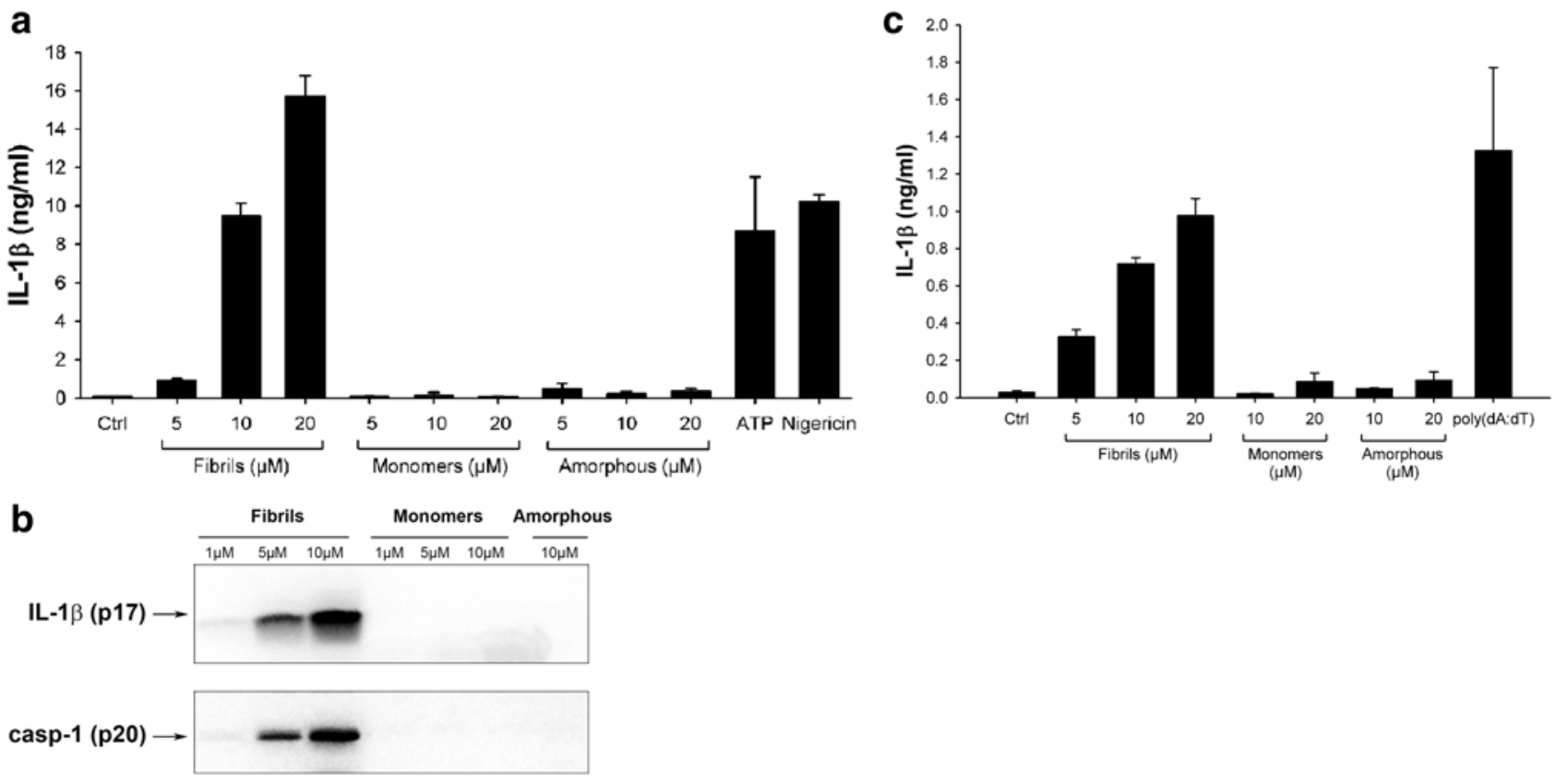

Fig. 2 Lysozyme fibrils, but not amorphous aggregates, induce IL-1 $\beta$ secretion. a, b PMA-primed THP1 cells were incubated for $6 \mathrm{~h}$ with the indicated amounts of either lysozyme fibrils, amorphous aggregates or monomers, ATP $(2 \mathrm{mM})$ or Nigericin $(10 \mu \mathrm{M})$. Cell supernatants were analyzed by ELISA (a) or immunoblotting for IL-1 $\beta$ (b, upper panel) and for activated caspase-1 (casp-1) (b, lower panel);

c LPS-primed mouse BMDMs were stimulated for $21 \mathrm{~h}$ with the indicated amounts of either lysozyme fibrils, monomers, or amorphous aggregates, or transfected with poly(dA:dT) $(5 \mu \mathrm{g} / \mathrm{ml})$, and cell supernatants were analyzed for IL- $1 \beta$ by ELISA. $n=3$, represented as mean \pm standard deviation (SD) 

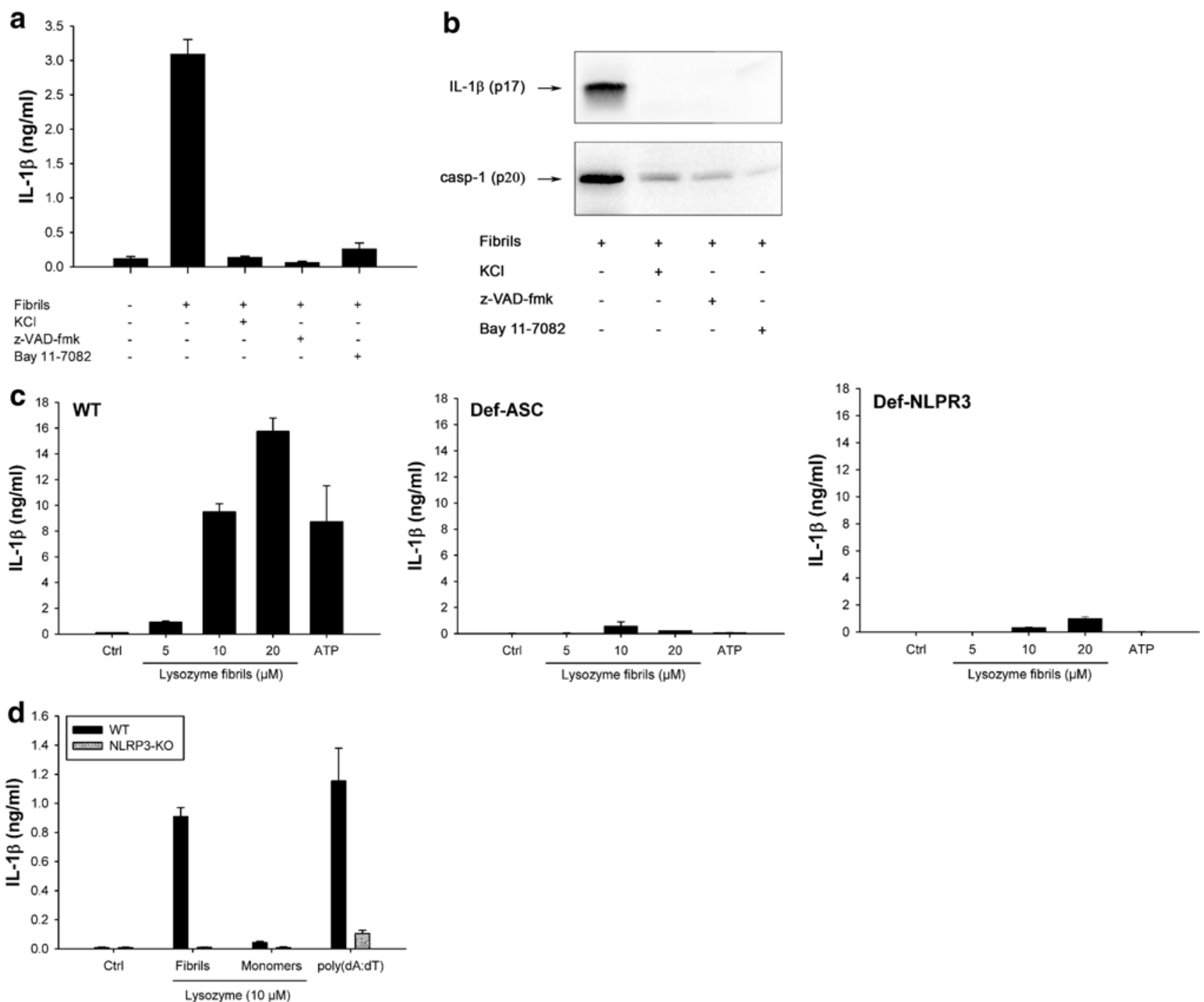

Fig. 3 Lysozyme fibrils activate the NLRP3 inflammasome. a, b PMA-primed THP1 cells were incubated for $6 \mathrm{~h}$ with $5 \mu \mathrm{M}$ lysozyme fibrils in the presence or absence of either $\mathrm{KCl}(130 \mathrm{nM})$, the pancaspase inhibitor $\mathrm{z}$-VAD-fmk $(20 \mu \mathrm{M})$, or the NLRP3 inhibitor Bay 11-7082 $(20 \mu \mathrm{M})$. Cell supernatants were analyzed for IL-1 $\beta$ by ELISA (a) and immunoblotting (b, upper panel) or for activated caspase-1 (casp-1) (b, lower panel); c PMA-primed WT, ASCdeficient (Def-ASC) and NLRP3-deficient (Def-NLRP3) THP1 cells

Fibrillar lysozyme activates the NLRP3 inflammasome

Further confirming the involvement of inflammasome, fibril-induced IL-1 $\beta$ secretion and caspase- 1 activation were inhibited by $\mathrm{KCl}$, which prevents the potassium efflux that is essential for inflammasome activation [38] and by the pan-caspase inhibitor z-VAD-fmk (Fig. 3a, b). Among the five inflammasomes described to date, the NLRP3 inflammasome is the most likely candidate for fibril-induced IL- $1 \beta$ secretion, because other aggregated and particulate substrates have been shown to activate this complex [39]. Supporting were incubated for $6 \mathrm{~h}$ with ATP $(2 \mathrm{mM})$ or the indicated amounts of lysozyme fibrils, and IL- $1 \beta$ was quantified by ELISA in the cell supernatant; d LPS-primed BMDMs from WT (black bars) or NLRP3 KO (grey bars) mice were stimulated for $21 \mathrm{~h}$ with the indicated amounts of either lysozyme fibrils or monomers, or transfected with poly(dA:dT) $(5 \mu \mathrm{g} / \mathrm{ml})$, and cell supernatants were analyzed for IL- $1 \beta$ by ELISA. $n=3$, mean \pm SD

this assumption, Bay 11-7082, a compound known to block NLRP3 [40] abrogated fibril-induced IL-1 $\beta$ secretion and caspase-1 activation (Fig. 3a, b). In ASC-deficient THP1 cells (THP1-DefASC), where ASC was knocked down by RNA interference, no cleaved IL- $1 \beta$ was produced in the presence of lysozyme fibrils (Fig. 3c, middle panel), showing that this adaptor protein is required for inflammasome activation. THP1-DefNLRP3 also did not produce IL-1 $\beta$ in response to fibrillar lysozyme (Fig. 3c, right panel), unambiguously demonstrating that the NLRP3 inflammasome is responsible for lysozyme fibril-mediated IL- $1 \beta$ secretion. As 
expected [36], ATP-induced IL-1 $\beta$ release was also dependent on ASC and NLRP3 proteins (Fig. 3c).

Again, similar results were obtained in primary BMDMs (Fig. 3d): lysozyme fibrils induced a concentrationdependent secretion of mature IL- $1 \beta$ from LPS-primed WT BMDMs, but not from NLRP3 knockout BMDMs (Fig. 3d).

Fibrillar aggregates of lysozyme, but not amorphous aggregates, induce IL-1 $\beta$ secretion from non-primed cells

The production of IL- $1 \beta$ is a two-step process with the first step requiring the synthesis of pro-IL- $1 \beta$. In vitro, the first signal is generally induced by priming cells with compounds such as PMA or LPS [12, 35] (Figs. 2, 3). In vivo, it is unclear which signals prime cells for inflammasome activation. In amyloidogenic diseases, we hypothesized that amyloid fibrils may themselves induce cellular priming. To test this hypothesis, we added lysozyme fibrils to unprimed THP1 cells and mouse primary macrophages. Lysozyme fibrils still induced concentration-dependent secretion of IL-1 $\beta$ from THP1 cells (Fig. 4a) and mouse primary BMDMs (Fig. 4e) albeit at lower levels than seen in primed cells (Fig. 2). Conversely, lysozyme monomers and amorphous aggregates did not induce any secretion of IL-1 $\beta$ in unprimed THP1 cells or BMDMs (Fig. $4 \mathrm{a}$, e), as expected since they both failed to activate the inflammasome in primed cells (Fig. 2).

Transcription of the IL-1 $\beta$ gene is controlled by the transcriptional activator NF- $\mathrm{kB}$ [10]. Therefore, to examine whether lysozyme fibrils activate the NF- $\kappa \mathrm{B}$ pathway, we used a THP1 cell line stably transfected with a NF-кB reporter (THP1-XBlue cells). Figure $4 \mathrm{~b}$ shows that incubation of THP1-XBlue cells with fibrillar aggregates of lysozyme led to the activation of NF- $\mathrm{BB}$ in a concentration-dependent manner (Fig. 4b, light grey). Lysozyme monomers and amorphous aggregates were again inactive (Fig. 4b, black and dark grey, respectively), even at the highest concentration tested.

As expected, NF- $\mathrm{KB}$ activation by lysozyme fibrils also leads to the secretion of high amounts of TNF- $\alpha$, in a concentration-dependent manner, in non-primed THP1 cells (Fig. 4c) and primary BMDMs (Fig. 4f), while no TNF- $\alpha$ production was detected in the presence of lysozyme monomers and amorphous aggregates. Finally, incubation of THP1 cells with lysozyme fibrils in the presence of the NF- $\kappa$ B inhibitor Bay 11-7082 abolished TNF- $\alpha$ secretion (Fig. 4d), further confirming the role of NF-kB in generating the inflammasome priming signal.

Lysozyme fibrils are recognized by the TLR1/TLR2 heterodimer

Figure 4 shows that fibrillar lysozyme activates the NF-кB pathway, but it is unclear which innate receptor is responsible for the sensing of fibrils. Toll-like receptors (TLRs) are good candidates for this sensing as many signaling cascades initiated by these receptors lead to the activation of NF- $\mathrm{BB}$. Therefore, we incubated THP1 cells with lysozyme fibrillar aggregates in the presence of blocking antibodies raised against different TLRs. While neutralizing antibodies prevented the activation of TLR2, TLR4, and TLR5 by their respective ligands (Fig. 5a), only the anti-TLR2 antibody abrogated fibril-induced TNF- $\alpha$ secretion (Fig. $5 b$ ). Fibril signaling indeed remained unchanged in the presence of the anti-TLR4 and anti-TLR5 antibodies, ruling out any involvement of TLR4 or TLR5 in fibril-sensing. This suggests that the induction of cytokine expression by lysozyme fibrils is mediated through TLR2.

Activation of NF-KB in TLR2-expressing HEK 293 cells (Materials and methods) by fibrillar lysozyme confirmed the role of this receptor in fibril detection (Fig. 5c, black bars), whereas lysozyme monomers or amorphous aggregates (data not shown) did not activate these cells. TLR2 signaling can be enhanced in the presence of CD14 [41], a glycoprotein involved in the recognition mechanism of several TLR2 substrates. CD14 is not, however, required for the recognition of lysozyme fibrils, as no additional enhancement in NF- $\mathrm{B}$ activation was observed in HEK 293 cells expressing TLR2 and CD14 (Fig. 5c, grey bars). TLR4expressing HEK 293 cells did not show activation of NF- $\mathrm{KB}$ in response to fibrillar lysozyme (Fig. 5d), confirming that TLR4 is not implicated in the inflammatory cascade triggered by lysozyme fibrils.

TLR2 functions as a heterodimer cooperating with TLR1 to recognize triacetylated lipopeptides, or with TLR6 to sense diacetylated mycoplasmal lipopeptides [11]. To identify which receptor(s) TLR2 associates with in response to lysozyme amyloid fibrils, we used the neutralizing antibody strategy. Antibodies raised against TLR1 and TLR6 prevented the activation of these receptors by their specific ligands (Fig. 5e). Whereas the anti-TLR6 antibody had only a moderate effect on the secretion of TNF- $\alpha$ induced by lysozyme fibrils, the anti-TLR1 antibody completely abolished this cytokine production (Fig. 5f). These results suggest that lysozyme fibrils are primarily sensed by the TLR2/TLR1 heterodimer, with TLR2/TLR6 playing a more minor role.

\section{Discussion}

Here, we show that lysozyme amyloid fibrils, but not non-fibrillar aggregates nor monomers, trigger caspase1-dependent processing of IL-1 $\beta$ through activation of the NLRP3 inflammasome in human cell lines and mouse primary macrophages. The NLRP3 inflammasome has been the most extensively studied NLR. One of the most 

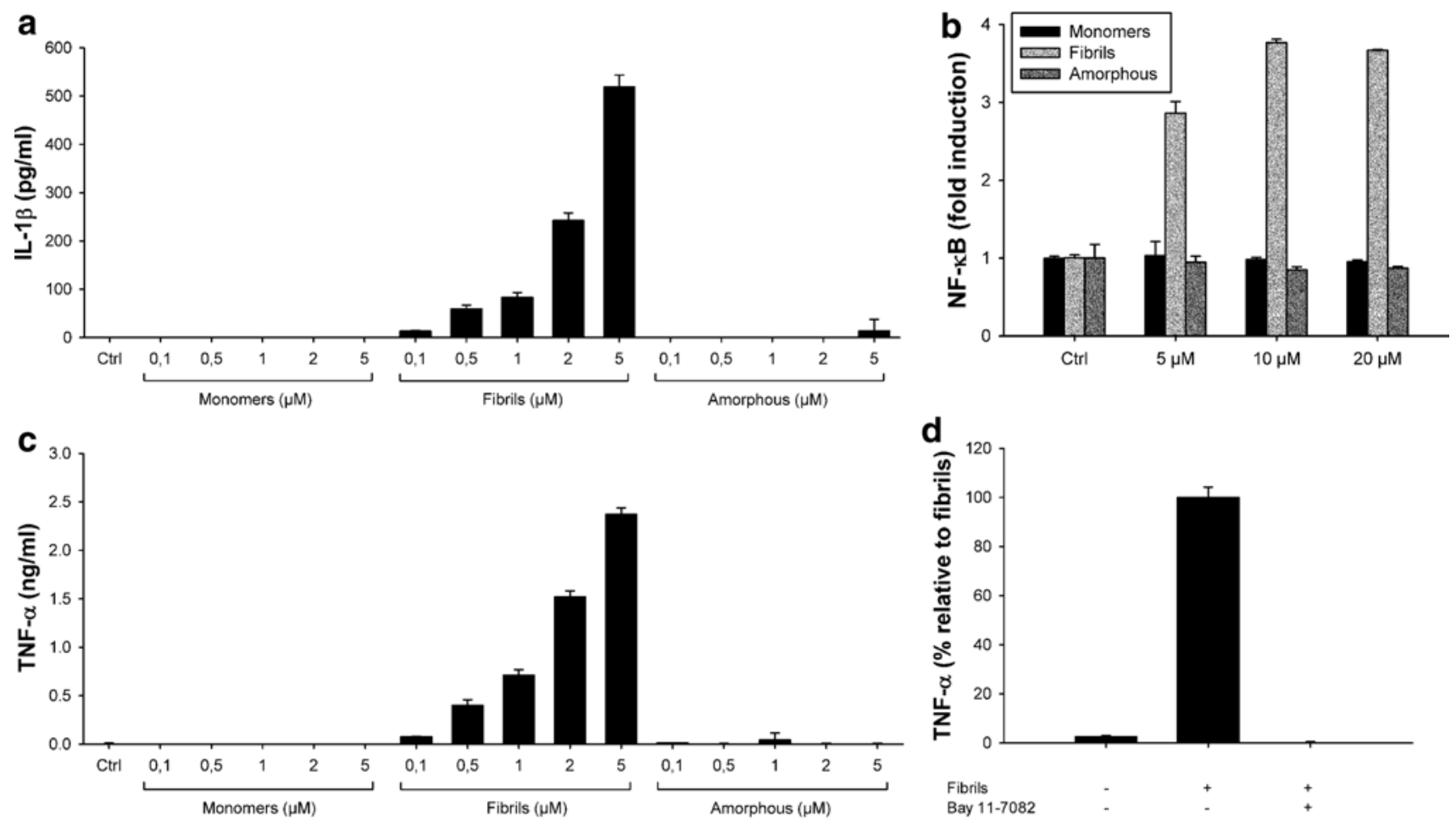

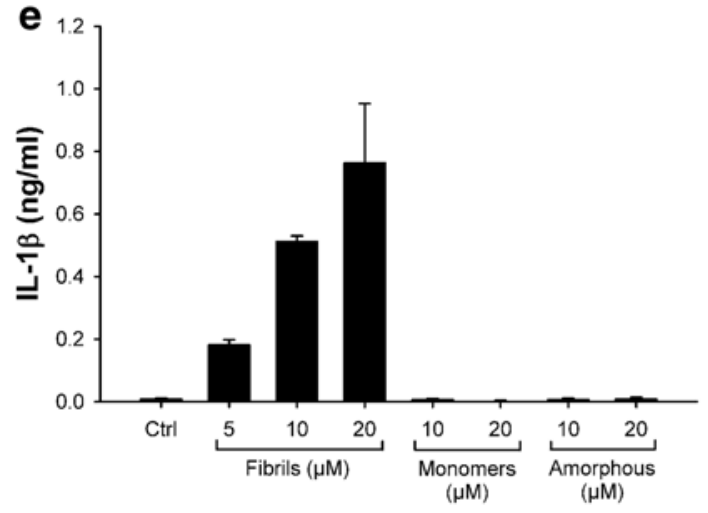

Fig. 4 Lysozyme fibrils induce IL-1 $\beta$ secretion from non-primed cells through NF-кB activation. a, c Unprimed THP1 cells were incubated for $6 \mathrm{~h}$ with the indicated amounts of either lysozyme fibrils, monomers, or amorphous aggregates. IL-1 $\beta$ (a) and TNF- $\alpha$ (c) were quantified in the cell supernatants by ELISA; b THP1-XBlue cells were incubated for $6 \mathrm{~h}$ with the indicated amounts of either lysozyme fibrils (light grey), amorphous aggregates (dark grey), or monomers (black). The phosphatase secreted upon NF-кB activation was

confusing aspects of its biology is that it is activated in response to a myriad of structurally unrelated compounds (for a review, see [42]), including muramyl dipeptide, bacterial toxins, extracellular ATP, skin irritants, particulate and crystalline substances such as asbestos fibers and silica particles, cholesterol, monosodium urate crystals, or several amyloid aggregates [7, 9]. The precise mechanisms by which NLRP3 recognizes such a diverse range of substances is unclear, but it is likely to involve an intermediate detected using the Quanti Blue assay (Materials and methods); d THP1 cells were incubated for $6 \mathrm{~h}$ with $5 \mu \mathrm{M}$ lysozyme fibrils, in the presence or absence of $20 \mu \mathrm{M}$ of the NF- $\mathrm{kB}$ inhibitor Bay 11-7082. Cell supernatants were assayed for TNF- $\alpha$ by ELISA; e, f Unprimed primary BMDMs were stimulated for $21 \mathrm{~h}$ with the indicated amounts of either lysozyme fibrils, monomers, or amorphous aggregates, or with LPS $(100 \mathrm{ng} / \mathrm{ml})$, and cell supernatants were analyzed for IL- $1 \beta$ (e) or TNF- $\alpha(\mathbf{f})$ by ELISA. $n=3$, mean \pm SD

factor common to different activators. Physical properties have been suggested to be the key for some classes of ligands [43, 44], as many present crystalline, aggregated, or particulate forms. Our data demonstrate that particulate structure alone is insufficient to activate NLRP3, as another aggregated state of lysozyme failed to induce inflammatory responses. Literature reports other cases of particulate substances activating the NLRP3 inflammasome that loose this property when slightly modified. Morishige et al. [45] 

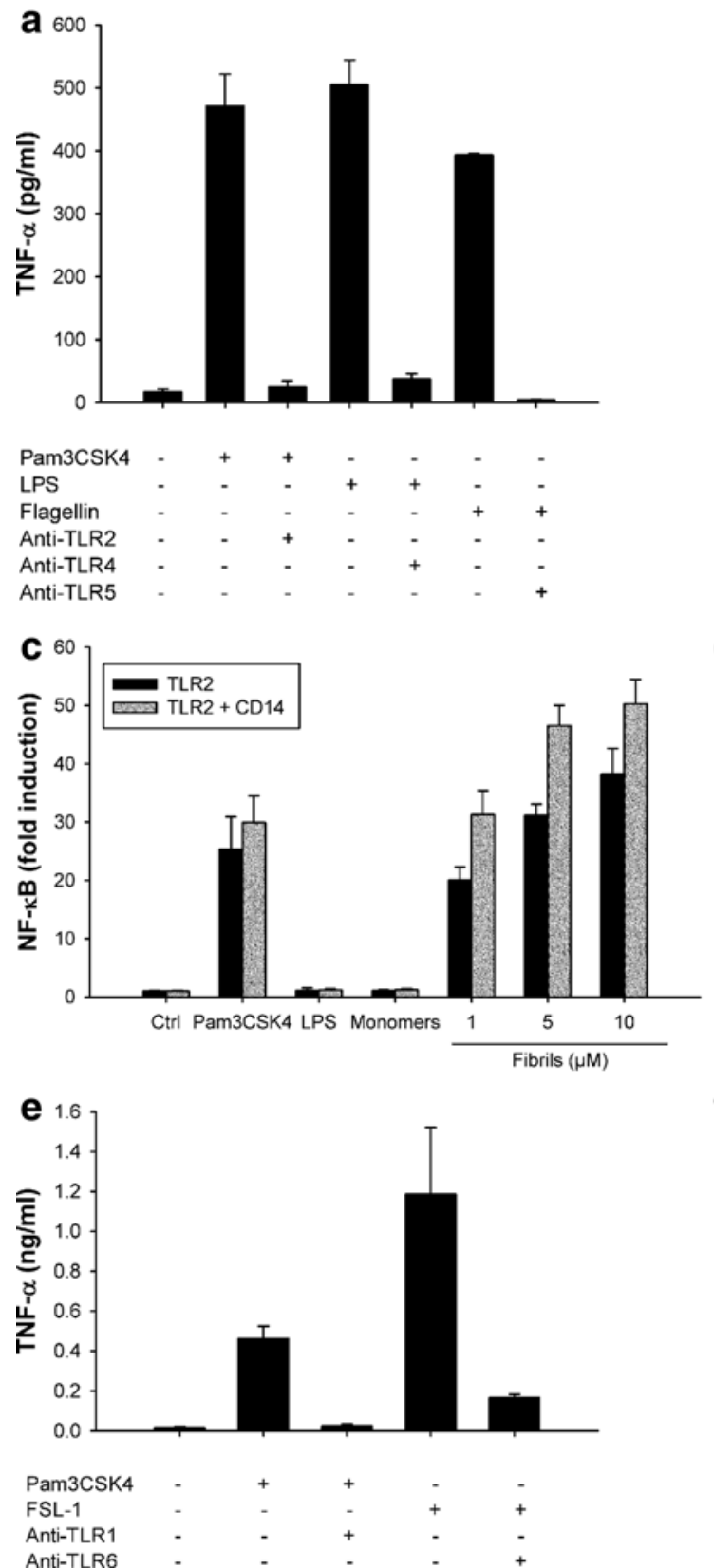

Fig. 5 Lysozyme fibrils activate the TLR2/TLR1 heterodimer. a, b THP1 cells were incubated for $6 \mathrm{~h}$ with $1 \mathrm{ng} / \mathrm{ml}$ Pam3CSK4, 5 $\mathrm{ng} / \mathrm{ml}$ LPS, $100 \mathrm{ng} / \mathrm{ml}$ flagellin (a) or with $5 \mu \mathrm{M}$ lysozyme fibrils (b), in the presence or absence of $20 \mu \mathrm{g} / \mathrm{ml}$ anti-TLR2, anti-TLR4, or anti-TLR5 antibodies. TNF- $\alpha$ was quantified in the cell supernatant by ELISA; c, d HEK 293 cells expressing TLR2 (c) or TLR4 and MD2 (d) with or without CD14 (grey and black bars, respectively) were incubated $6 \mathrm{~h}$ in the presence of Pam3CSK4 (10 ng/ $/ \mathrm{l})$, LPS

showed that silica particles, which are strong NLRP3 activators, become immunologically inactive when modified with specific functional groups, though the physical structure of these particles was unchanged. Polystyrene beads or diesel exhaust particles do not engage the NLRP3 inflammasome

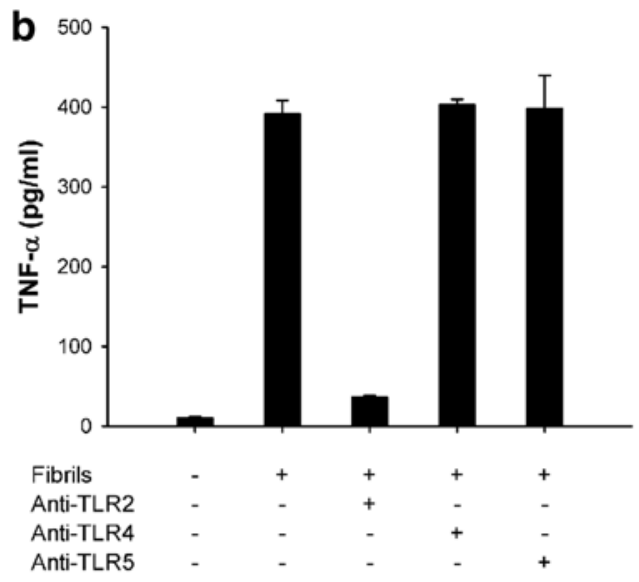

d
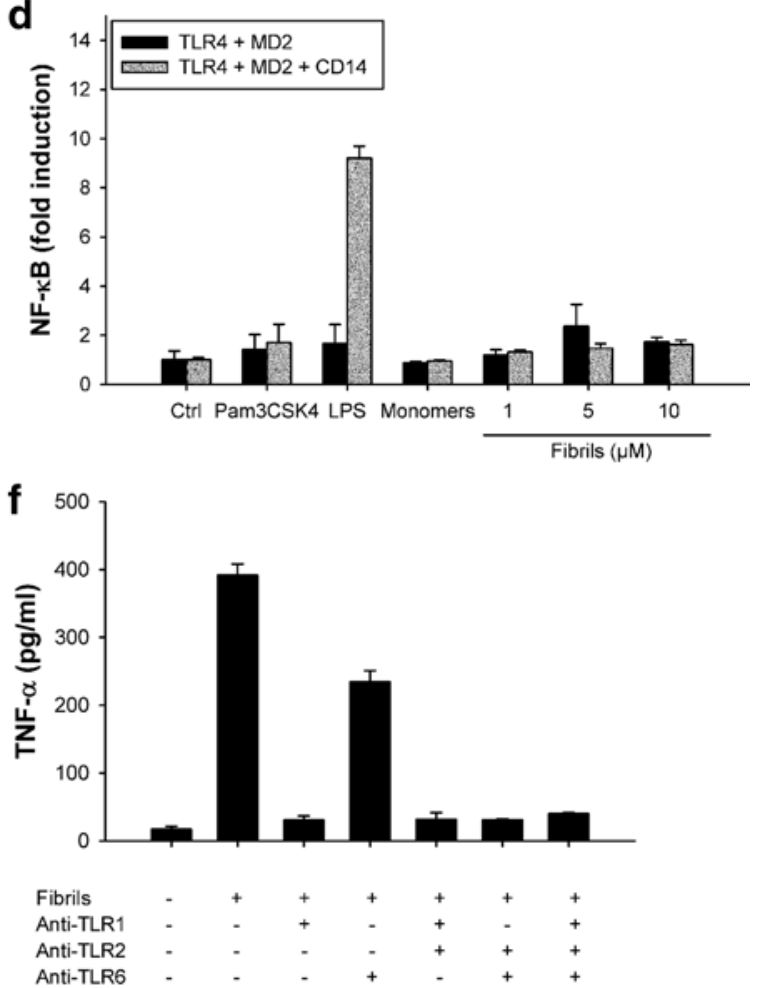

(100 $\mathrm{ng} / \mu \mathrm{l})$, or the indicated concentrations of either lysozyme monomers or fibrils. NF-kB activation was detected by quantifying luciferase activity in cell lysates; e, f THP1 cells were incubated for $6 \mathrm{~h}$ with $1 \mathrm{ng} / \mathrm{ml}$ Pam3CSK4, $100 \mathrm{ng} / \mathrm{ml}$ FSL-1, or with $5 \mu \mathrm{M}$ lysozyme fibrils, in the presence or absence of $20 \mu \mathrm{g} / \mathrm{ml}$ anti-TLR2, anti-TLR1, or anti-TLR6 antibodies. TNF- $\alpha$ was quantified in the cell supernatants by ELISA. $n=3$, mean $\pm \mathrm{SD}$

[46] despite their particulate nature. The characteristics of particulate substances required to activate NLRP3, however, remain to be clarified, but in the case of amyloid fibrils, our work present new evidence to propose that the key may reside in specific structural features. 
Fibrils of other amyloidogenic proteins have been shown to trigger inflammasome cascades. Amyloid- $\beta$ (A $\beta$ ) fibrils, whose extracellular accumulation in senile plaques is the hallmark of Alzheimer's disease, induce the secretion of IL-1 $\beta$ through activation of the NLRP3 inflammasome [7]. Fibrillar aggregates of superoxide dismutase 1 (SOD1), the causative agent of amyotrophic lateral sclerosis (ALS), also trigger IL-1 $\beta$ secretion, although via a NLRP3-independent mechanism [13]. In both cases, the inflammatory properties have clearly been related to the fibrillar state of the protein. On the other hand, two recent works investigating the inflammatory properties of islet amyloid polypeptide (IAPP), whose fibrillar deposits are found in the pancreas of patients with type II diabetes, pointed oligomers as the immunologically active species $[9,14]$. However, since aggregation of IAPP is extremely rapid [47, 48] and the presence of lipidic bilayers or cell membranes further accelerates this process $[47,49,50]$, it is very difficult to identify precisely the entities responsible for cellular activation, and to know whether they contain cross- $\beta$ structures. In contrast, the different species used in our work are stable. Fibrils and amorphous aggregates are end-products of aggregation, and WT lysozyme does not aggregate under physiological conditions.

Our results also demonstrate that amyloid fibrils induce the secretion of IL- $1 \beta$ from unprimed cells, implying that the aggregated protein could also accommodate the priming step through activation of a second pattern-recognition receptor (PRR), TLR2. In addition to provide inflammasome priming, TLR2 activation by lysozyme fibrils also leads to the secretion of many important inflammatory mediators, such as TNF- $\alpha$, by activating the transcription factor NF- $\kappa$ B. The ability of amyloid fibrils to prime cells as well as drive inflammasome activity suggests a mechanistic basis for the inflammatory pathogenesis associated with many amyloidoses. There is compelling evidence that TLR2 recognizes fibrils of other amyloidogenic proteins. The bacterial protein CsgA form fibrillar structures, called Curli fibrils, that mediate biofilm formation [51]. These bacterial fibrils activate TLR2, and the process proved to be fibril-specific [52]. A $\beta$ fibrils trigger the expression of TNF- $\alpha$ through a mechanism involving activation of TLR2 and TLR4, but non-fibrillar $A \beta$ does not $[52,53]$.

How such large complexes are recognized by PRRs is unclear. It has recently been shown that TLR3 is able to recognized long double-stranded RNA through lateral clustering of TLR3 units along the length of the dsRNA ligand [54]. Fibril recognition by TLR2 could occur in a similar way along the fibril. Alternatively, small protein entities could break away from the fibril and bind the receptor, as observed for ultra-high weight polyethylene [55], or require an unidentified intermediary protein capable of extracting the appropriate species from the fibril. More studies are therefore required to understand the recognition mechanism of such large entities by innate immune receptors.

Finally, our results demonstrate that human lysozyme activates both TLR2 and NLRP3 when folded as amyloid fibrils, but fails to induce the same cascades when folded as monomers or as another type of aggregate. Consequently, we suggest that the inflammatory properties of lysozyme fibrils are related to their intrinsic structure. As explained above, fibrillar aggregates of other amyloidogenic proteins have been shown to activate TLR2 and/or NLRP3. Amyloidogenic proteins harbor different sequences and native structures, but present the same fibrillar character, with the typical cross- $\beta$ structure [56], when they aggregate into fibrils. This structure can easily be detected with the specific ThT fluorescent probe [32]. Furthermore, amyloid fibrils cross- $\beta$ structure is generally composed of parallel $\beta$-sheets, which can be detected using IR spectroscopy [25, 26]. Unlike lysozyme fibrils, the immunologically inactive amorphous aggregates do not contain this characteristic structural motif, despite sharing the same sequence. They did not enhance ThT fluorescence, and their $\beta$-sheet content was only anti-parallel. Moreover, they were not detected by a conformation-dependent antibody specifically recognizing amyloid fibrils. On the basis of these results, it seems reasonable to suggest that the immune system responds more specifically to several structural features of fibrils rather than to an aggregated state or to a specific sequence motif.

In conclusion, our work, combining structural and immunological data, clearly demonstrates that lysozyme fibrils are immunologically active species, and strongly suggests that their cross- $\beta$ sheet structure is critical for driving inflammatory responses to these aggregates. As a result, it is tempting to speculate that amyloid fibrils represent a new class of danger signals detected by the innate immune system, through sensing of their common cross- $\beta$ structure, a motif common to all amyloids irrespective of their origin [56]. Fibrils of microbial origin would indicate pathogen invasion, since amyloids are widely distributed among several bacterium phyla [57], and would allow the immune system to detect an ongoing infection, thus representing a new class of pathogen-associated molecular pattern. Fibrils of endogenous origin, arising from abnormal protein aggregation as in the case of amyloidogenic disorders, would warn the immune system of anomalous protein aggregation, thus constituting a new type of danger-associated molecular pattern. Therefore, we propose that cross- $\beta$ structure could be used by innate immunity as a generic pattern to detect exogenous as well as endogenous threats.

Acknowledgments The authors thank Dr. Emilie Cerf for critical reading of the manuscript and Dr. Rabia Sarroukh for helpful comments and discussion. CL is a Postdoctoral Researcher, MD and VR are Senior Research Associates at the Belgian National Fund for Scientific Research (F.R.S. - FNRS). This work was in part supported by 
the Belgian Government (IAP P6/19) to MD and a BBSRC Research Development Fellowship (CEB).

Conflicts of interest The authors declare that they have no conflict of interest.

Ethical standards The experiments performed for this study comply with the current laws of Belgium and United Kingdom.

\section{References}

1. Chiti F, Dobson CM (2006) Protein misfolding, functional amyloid, and human disease. Annu Rev Biochem 75:333-366. doi:10.1146/annurev.biochem.75.101304.123901

2. Koo EH, Lansbury PT Jr, Kelly JW (1999) Amyloid diseases: abnormal protein aggregation in neurodegeneration. Proc Natl Acad Sci USA 96:9989-9990. doi:10.1073/pnas.96.18.9989

3. Nelson R, Eisenberg D (2006) Recent atomic models of amyloid fibril structure. Curr Opin Struct Biol 16:260-265. doi:10.1016/j.sbi.2006.03.007

4. GreenwaldJ,RiekR(2010)Biologyofamyloid:structure, function, and regulation. Structure 18:1244-1260. doi:10.1016/j.str.2010.08.009

5. Castellani RJ, Rolston RK, Smith MA (2010) Alzheimer disease. Dis Mon 56:484-546. doi:10.1016/j.disamonth.2010.06.001

6. Gao HM, Hong JS (2008) Why neurodegenerative diseases are progressive: uncontrolled inflammation drives disease progression. Trends Immunol 29:357-365. doi:10.1016/j.it.2008.05.002

7. Halle A et al (2008) The NALP3 inflammasome is involved in the innate immune response to amyloid-beta. Nat Immunol 9:857865. doi:10.1038/ni.1636

8. Zhang W et al (2005) Aggregated alpha-synuclein activates microglia: a process leading to disease progression in Parkinson's disease. FASEB J 19:533-542. doi:10.1096/fj.04-2751com

9. Masters SL et al (2010) Activation of the NLRP3 inflammasome by islet amyloid polypeptide provides a mechanism for enhanced IL-1beta in type 2 diabetes. Nat Immunol 11:897-904. doi:10.1038/ni.1935

10. Dinarello CA (2001) IL-I $\beta$, in the cytokine reference. Oppenheim JJ, Feldman M (eds) Academic Press, London, p 351. doi: 10.1006/rwcy.2000.04004. ftp://195.214.211.1/books/DVD-022/ DinarcIIo_C._IL-1b_\%282000\%29\%28en\%29\%2824s\%29.pdf

11. Takeuchi O, Akira S (2010) Pattern recognition receptors and inflammation. Cell 140:805-820. doi:10.1016/j.cell.2010.01.022

12. Bauernfeind $F$ et al (2011) Inflammasomes: current understanding and open questions. Cell Mol Life Sci 68:765-783. doi:10.1007/ s00018-010-0567-4

13. Meissner F, Molawi K, Zychlinsky A (2010) Mutant superoxide dismutase 1-induced IL-1beta accelerates ALS pathogenesis. Proc Natl Acad Sci USA 107:13046-13050. doi:10.1073/p nas. 1002396107

14. Westwell-Roper C et al (2011) IL-1 blockade attenuates islet amyloid polypeptide-induced proinflammatory cytokine release and pancreatic islet graft dysfunction. J Immunol 187:2755-2765. doi: 10.4049/jimmunol.1002854

15. Granel B et al (2006) Lysozyme amyloidosis: report of 4 cases and a review of the literature. Medicine (Baltimore) 85:66-73. doi:10.1097/01.md.0000200467.51816.6d

16. Dumoulin M, Kumita JR, Dobson CM (2006) Normal and aberrant biological self-assembly: insights from studies of human lysozyme and its amyloidogenic variants. Acc Chem Res 39:603610. doi:10.1021/ar050070g

17. Johnson RJ et al (2005) Rationalising lysozyme amyloidosis: insights from the structure and solution dynamics of T70N lysozyme. J MolBiol352:823-836. doi:10.1016/j.jmb.2005.07.040
18. Calamai M et al (2006) Nature and significance of the interactions between amyloid fibrils and biological polyelectrolytes. Biochemistry 45:12806-12815. doi:10.1021/bi0610653

19. Walsh $\mathrm{C}$ et al (2008) Elucidation of the MD-2/TLR4 interface required for signaling by lipid IVa. J Immunol 181:1245-1254

20. Goormaghtigh E, Raussens V, Ruysschaert JM (1999) Attenuated total reflection infrared spectroscopy of proteins and lipids in biological membranes. Biochim Biophys Acta 1422:105-185. doi:10.1016/S0304-4157(99)00004-0

21. Goormaghtigh E, Cabiaux V, Ruysschaert JM (1990) Secondary structure and dosage of soluble and membrane proteins by attenuated total reflection Fourier-transform infrared spectroscopy on hydrated films. Eur J Biochem 193:409-420. doi:10.1111/j.1432-1033.1990.tb19354.x

22. Dumoulin M et al (2003) A camelid antibody fragment inhibits the formation of amyloid fibrils by human lysozyme. Nature 424:783-788. doi:10.1038/nature01870

23. Mossuto MF et al (2010) The non-core regions of human lysozyme amyloid fibrils influence cytotoxicity. J Mol Biol 402:783-796. doi:10.1016/j.jmb.2010.07.005

24. Peralvarez-Marin A, Barth A, Graslund A (2008) Timeresolved infrared spectroscopy of $\mathrm{pH}$-induced aggregation of the Alzheimer Abeta(1-28) peptide. J Mol Biol 379:589-596. doi:10.1016/j.jmb.2008.04.014

25. Chirgadze YN, Nevskaya NA (1976) Infrared spectra and resonance interaction of amide-I vibration of the parallel-chain pleated sheets. Biopolymers 15:627-636. doi:10.1002/bip.1976.360150403

26. Goormaghtigh E, Cabiaux V, Ruysschaert JM (1994) Determination of soluble and membrane protein structure by Fourier transform infrared spectroscopy. I. Assignments and model compounds. Subcell Biochem 23:329-362. doi:10.1007/978-1-4615-1863-1

27. Antzutkin ON et al (2000) Multiple quantum solid-state NMR indicates a parallel, not antiparallel, organization of beta-sheets in Alzheimer's beta-amyloid fibrils. Proc Natl Acad Sci USA 97:13045-13050. doi:10.1073/pnas.230315097

28. Margittai M, Langen R (2008) Fibrils with parallel in-register structure constitute a major class of amyloid fibrils: molecular insights from electron paramagnetic resonance spectroscopy. Q Rev Biophys 41:265-297. doi:10.1017/S0033583508004733

29. Celej MS et al (2012) Toxic prefibrillar alpha-synuclein amyloid oligomers adopt a distinctive antiparallel beta-sheet structure. Biochem J 443:719-726. doi:10.1042/BJ20111924

30. Cerf $E$ et al (2009) Antiparallel beta-sheet: a signature structure of the oligomeric amyloid beta-peptide. Biochem J 421:415-423. doi: 10.1042/BJ20090379

31. Chirgadze YN, Nevskaya NA (1976) Infrared spectra and resonance interaction of amide-I vibration of the antiparallelchain pleated sheet. Biopolymers 15:607-625. doi:10.1002/ bip. 1976.360150402

32. Biancalana M, Koide S (2010) Molecular mechanism of Thioflavin-T binding to amyloid fibrils. Biochim Biophys Acta 1804:1405-1412. doi:10.1016/j.bbapap.2010.04.001

33. Kayed R et al (2007) Fibril specific, conformation dependent antibodies recognize a generic epitope common to amyloid fibrils and fibrillar oligomers that is absent in prefibrillar oligomers. Mol Neurodegener 2:18. doi:10.1186/1750-1326-2-18

34. Kayed R et al (2003) Common structure of soluble amyloid oligomers implies common mechanism of pathogenesis. Science 300:486-489. doi:10.1126/science. 1079469

35. Bauernfeind FG et al (2009) Cutting edge: NF-kappaB activating pattern recognition and cytokine receptors license NLRP3 inflammasome activation by regulating NLRP3 expression. J Immunol 183:787-791. doi:10.4049/jimmunol.0901363

36. Mariathasan $\mathrm{S}$ et al (2006) Cryopyrin activates the inflammasome in response to toxins and ATP. Nature 440:228-232. doi:10.1038/ nature 04515 
37. Bryant C, Fitzgerald KA (2009) Molecular mechanisms involved in inflammasome activation. Trends Cell Biol 19:455-464. doi:10.1016/j.tcb.2009.06.002

38. Petrilli V et al (2007) Activation of the NALP3 inflammasome is triggered by low intracellular potassium concentration. Cell Death Differ 14:1583-1589. doi:10.1038/sj.cdd.4402195

39. Cassel SL, Sutterwala FS (2010) Sterile inflammatory responses mediated by the NLRP3 inflammasome. Eur J Immunol 40:607611. doi:10.1002/eji.200940207

40. Juliana $\mathrm{C}$ et al (2010) Anti-inflammatory compounds parthenolide and Bay 11-7082 are direct inhibitors of the inflammasome. J Biol Chem 285:9792-9802. doi:10.1074/jbc.M109.082305

41. Miyake K (2006) Roles for accessory molecules in microbial recognition by Toll-like receptors. J Endotoxin Res 12:195-204. doi: 10.1179/096805106X118807

42. Schroder K, Tschopp J (2010) The inflammasomes. Cell 140:821832. doi:10.1016/j.cell.2010.01.040

43. Hornung V et al (2008) Silica crystals and aluminum salts activate the NALP3 inflammasome through phagosomal destabilization. Nat Immunol 9:847-856. doi:10.1038/ni.1631

44. Martinon F (2010) Signaling by ROS drives inflammasome activation. Eur J Immunol 40:616-619. doi:10.1002/eji.200940168

45. Morishige $T$ et al (2010) The effect of surface modification of amorphous silica particles on NLRP3 inflammasome mediated IL-1beta production, ROS production and endosomal rupture. Biomaterials 31:6833-6842. doi:10.1016/j.biomaterials.2010.05.036

46. Dostert $\mathrm{C}$ et al (2008) Innate immune activation through Nalp3 inflammasome sensing of asbestos and silica. Science 320:674677. doi:10.1126/science.1156995

47. Khemtemourian L, Killian JA, Hoppener JW, Engel MF (2008) Recent insights in islet amyloid polypeptide-induced membrane disruption and its role in beta-cell death in type 2 diabetes mellitus. Exp Diabetes Res 2008:421287. doi:10.1155/2008/421287
48. Patil SM, Mehta A, Jha S, Alexandrescu AT (2011) Heterogeneous amylin fibril growth mechanisms imaged by total internal reflection fluorescence microscopy. Biochemistry 50:2808-2819. doi:10.1021/bi101908m

49. Hebda JA, Miranker AD (2009) The interplay of catalysis and toxicity by amyloid intermediates on lipid bilayers: insights from type II diabetes. Annu Rev Biophys 38:125-152. doi:10.1146/ann urev.biophys.050708.133622

50. Knight JD, Miranker AD (2004) Phospholipid catalysis of diabetic amyloid assembly. J Mol Biol 341:1175-1187. doi:10.1016/j.jmb.2004.06.086

51. Chapman MR et al (2002) Role of Escherichia coli curli operons in directing amyloid fiber formation. Science 295:851-855. doi:10.1126/science.1067484

52. Tukel $\mathrm{C}$ et al (2009) Responses to amyloids of microbial and host origin are mediated through toll-like receptor 2. Cell Host Microbe 6:45-53. doi:10.1016/j.chom.2009.05.020

53. Udan ML, Ajit D, Crouse NR, Nichols MR (2008) Toll-like receptors 2 and 4 mediate Abeta(1-42) activation of the innate immune response in a human monocytic cell line. J Neurochem 104:524533. doi:10.1111/j.1471-4159.2007.05001.x

54. Luo J et al (2012) Lateral clustering of TLR3:dsRNA signaling units revealed by TLR3ecd:3Fabs quaternary structure. J Mol Biol doi. doi:10.1016/j.jmb.2012.05.006

55. Maitra R et al (2009) Endosomal damage and TLR2 mediated inflammasome activation by alkane particles in the generation of aseptic osteolysis. Mol Immunol 47:175-184. doi:10.1016/j.molimm.2009.09.023

56. Dobson CM (1999) Protein misfolding, evolution and disease. Trends Biochem Sci 24:329-332. doi:10.1016/S0968-0004(99)01445-0

57. Gebbink MF, Claessen D, Bouma B, Dijkhuizen L, Wosten HA (2005) Amyloids - a functional coat for microorganisms. Nat Rev Microbiol 3:333-341. doi:10.1038/nrmicro1127 